\title{
aniki
}

Revista Portuguesa da Imagem em Movimento

Portuguese Journal of the Moving Image

\section{Lúcida esquizofrenia latinolusoafricana: o colóquio 'Ruy Guerra e o Pensamento Crítico das Imagens' Beatriz Rodovalho ${ }^{1}$}

Ruy Guerra e o Pensamento Crítico das Imagens - colóquio internacional, Paris, França, 7-9 de outubro de 2015.

"Eu só tenho como país essa insônia teimosa dentro de um sonho vivo". O verso do poema "Meu País" de Ruy Guerra², dito pela voz mistificante de Rita Chaves (Universidade de São Paulo), evoca o caráter errante, desassossegado e engajado que marca seu cinema. Guerra, que carrega em sua arte os traços de tantos deslocamentos em uma "esquizofrênica latino-africanidade" ${ }^{3}$, é um homem do presente, como afirma Vavy Pacheco Borges (Universidade Estadual de Campinas), historiadora e biógrafa do cineasta. Ele interessa-se pouco pela salvaguarda e pela escavação estética e historiográfica de sua obra, legando essa tarefa a pesquisadores como os mais de vinte que passaram pelo colóquio internacional Ruy Guerra e o Pensamento Crítico das Imagens, organizado por Raquel Schefer, Mickaël RobertGonçalves e Benjamin Léon ${ }^{4}$.

No entanto, como mostrou o colóquio, o trabalho sobre a arte de Guerra consiste em um embate com uma memória viva e em movimento, que se transforma e que assume novos sentidos no presente. Ela convoca, sobretudo, o espectador a se "dobrar diante da realidade" ${ }^{\circ}$ e de seus devires possíveis. Chama-o à insônia e ao sonho vivo. Como dar conta, nessas poucas páginas, de toda a reflexão acerca do projeto de Guerra que teve lugar nesses dias em Paris? Apresentamos aqui algumas questões que animaram as discussões em torno das mesas e projeções, sabendo que uma publicação dos

\footnotetext{
${ }^{1}$ Doutoranda na Université Sorbone Nouvelle - Paris 3, École Doctorale Arts et Médias, IRCAV, 75005 Paris, França.

${ }^{2}$ Moçambique, 1931. Citando a apresentação do colóquio, "cineasta, poeta, cançonetista, escritor e actor, todas estas categorias - ou a combinação de todas elas - se revelam insuficientes para definir a transversalidade e a riqueza transdisciplinar" de sua obra.

${ }^{3}$ Ruy Guerra, texto de abertura de Vinte Navios, citado por Rita Chaves.

${ }^{4}$ Raquel Schefer é doutora em Estudos Cinematográficos pela Universidade Sorbonne Nouvelle - Paris 3 (França). Parte de sua tese dedica-se a um estudo inédito de Mueda, Memória e Massacre (1979-1980). Ver: Schefer, R. 2015. La Forme-Événement. Le cinéma révolutionnaire mozambicain et le cinéma de Libération. Tese de doutoramento, Universidade Sorbonne Nouvelle - Paris 3, Paris, França. Mickaël Robert-Gonçalves e Benjamin Léon são doutorandos em Estudos Cinematográficos na mesma universidade.

${ }^{5}$ Segundo Vavy Pacheco Borges, para Guerra, essa é a posição daquele que decide fazer um cinema brasileiro.
} 
textos se faz necessária para a historiografia recente desse cinema que atravessa e que une as fronteiras de três continentes.

\section{Corpos políticos}

Uma sessão de filmes raros de Guerra, apresentada por Vavy Pacheco Borges, Jorge la Ferla (Universidad del Cine e Universidade de Buenos Aires) e Mateus Araújo Silva (Universidade de São Paulo), foi exibida na associação La Maudite ${ }^{6}$. Junto do público, os pesquisadores esboçaram um pensamento estético e histórico sobre esse conjunto heterogêneo de filmes. Operação Búfalo (1975), Um Povo Nunca Morre (1980) e Os Comprometidos: Actas de um Processo de Descolonização $(1985)^{7}$, filmes moçambicanos, permanecem um enigma, possuindo certos traços formais e discursivos da reportagem, do cinema de propaganda e mesmo do documentário colonial. Contudo, vê-se nesses filmes algo da essência do projeto estético de Guerra que se manifesta, por exemplo, em Os Cafajestes (1962) e em A Queda (1977). Além do emprego de formas fílmicas como a câmara na mão ou o plano sequência, o povo oprimido encontra-se no cerne de seus temas.

Vavy Pacheco Borges, que inaugurou as sessões esboçando a trajetória de Guerra, identifica a opressão e a injustiça como alvo de toda a "vida-obra"8 do cineasta. Para ele, vida, arte e luta política confundem-se. Como cita Vavy, Guerra declara que sua arte múltipla, que se apropria de todos os meios, resulta da falta de dinheiro. "Sou um produto do subdesenvolvimento", diz. Todavia, sua identificação com a margem é a essência desse emaranhado que é Guerra. Elziane Dourado (Universidade Federal do Rio de Janeiro), que discutiu as problemáticas de sua (vida-)obra, ressalta que Guerra ocupa a posição do intelectual segundo a definição de Edward Said: Guerra é um exilado, um marginal, um estranho, um amador, um perturbador. Além disso, é um descolonizador - “'descolonizar’ é, aí, conjugado no duplo sentido político e estético"9.

Wagner Morales (Universidade Sorbonne Nouvelle - Paris 3) também enfatizou que o ser-estar em deslocamento e à margem constitui um gesto político de exílio. Aliás, como cita o pesquisador, é o que reivindica Georges Didi-Huberman em sua análise da obra de Bertolt Brecht, autor de A Ópera dos Três Vinténs (1928), que está na origem de A Ópera do Malandro (o filme data de 1986). Como se trata aqui de descolonizar os espíritos e os discursos, pode-se dizer que

\footnotetext{
${ }^{6}$ Quand le soleil dort (1954, França, 10'), Operação Búfalo (1978, Moçambique, 25'). Um Povo Nunca Morre (1980, Moçambique, 17'), trechos de Os Comprometidos Acta 5, (1985, Moçambique, 42'), Obvious Child (1990, Estados Unidos, 5').

${ }^{7}$ Série de filmes feito para a televisão. Segundo José Luiz Cabaço e Raquel Schefer, houve uma emissão única na Televisão Experimental de Moçambique.

${ }^{8}$ Expressão empregada pelos organizadores.

${ }^{9}$ Texto de apresentação do colóquio.
} 
Guerra/Chico Buarque se apropriam do que já havia sido apropriado (Brecht inspira-se da Ópera dos Mendigos, de John Gay, 1724) para denunciar um certo imperialismo. Consequentemente, não seria não apenas o desterro mas também o deslocamento através da periferia o verdadeiro gesto do exílio?

Morales problematizou a "imagem da resistência e a imagem que resiste" a partir de Mueda, Memória e Massacre (1979-1980), mas também a partir de outros artistas que se colocam à distância dos acontecimentos e de outros massacres, como é o caso da performance The Pixelated Revolution (2012), de Rabih Mroué. A obra de Mroué analisa vídeos amadores do conflito sírio em que as câmaras se confundem com os corpos e registam o momento da morte de seus operadores. Contrariamente à abundância de imagens das vítimas dessa guerra, impõe-se a ausência de imagens do massacre de Mueda. Por meio do cinema, Guerra explora o que resta do acontecimento - a memória, a comemoração, e a imaginação que resiste ao esquecimento. José Luiz Cabaço (Universidade de São Paulo), figura central da história da independência de Moçambique, destaca que na tradição mística moçambicana é preciso "recriar as coisas para que as coisas vivam”. Nesse sentido, para Cabaço, Mueda, Memória e Massacre é um filme sobre a memória coletiva (uma memória sem sujeito, mas de todos os sujeitos) e a memória individual.

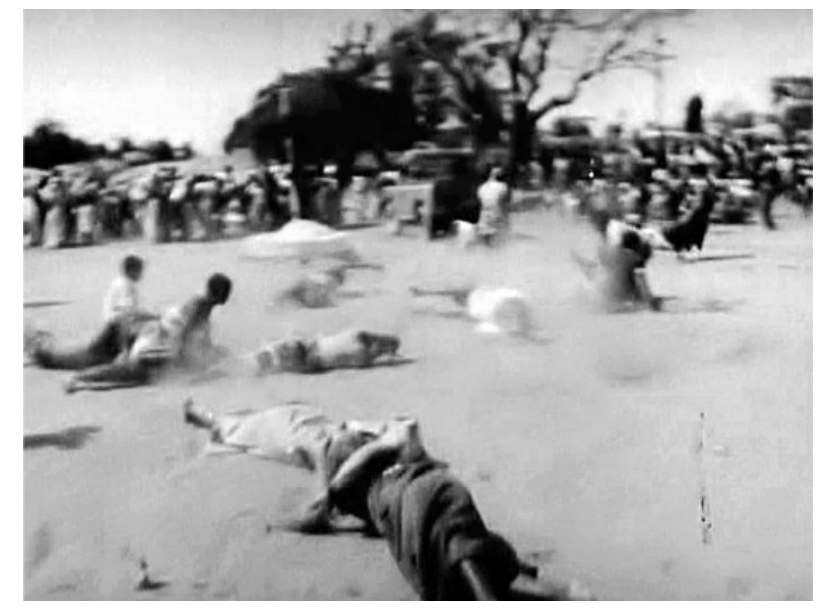

Imagem 1: Mueda, Memória e Massacre: a imagem como território de história e de memória (C) Ruy Guerra

Catarina Simão ${ }^{10}$ evoca o projeto de restauração do filme ${ }^{11}$. Ela apresenta os desafios de atualizá-lo sob a luz de sua história, feita de

\footnotetext{
${ }^{10}$ Ver Simão, Catarina. 2015. Uhuru. Stamp. Geneology. Anatomy. Bratislava: APART Labeland. (http://apart.sk/product/uhuru/). Ver também seu trabalho videográfico Mueda 1979 em www.catarinasimao.com. Acesso em maio, 2016.

${ }^{11}$ Ver http://www.arcadiafilm.de/en/index.php/projects/multimedia_installation/o_mundo_em_imagens dvd edition mit filmen aus mosambik. Acesso em maio, 2016.
} 
inúmeros cortes, censuras, versões e perdas. Após descrever uma projeção de Mueda, Memória e Massacre em Maputo, a artista conclui que os movimentos de "transposição de um teatro popular em filme" e a subsequente "passagem das imagens do passado" para o presente implicam um processo político. Necessariamente, o atual público moçambicano produz "camadas suplementares de compreensão política do filme”, em um processo memorial contínuo.

Se a memória do massacre transforma-se em imagem por meio da performance dos corpos do povo, existe um laço estreito entre o corpo e a terra. Guerra, atravessando territórios geográficos e simbólicos, tematiza também essa questão. Rita Chaves expõe a cartografia poética do cineasta, que transporta em seus deslocamentos suas raízes arrancadas (ou móveis) da terra natal. "A minha saudade é tão intensa, tão fisiológica, tão crua, que um pedaço de terra moçambicana, eu a comeria neste medo de perder a lembrança de seu sabor", escreve ele em seu poema "Apenas".

A posição do exilado manifesta-se então no próprio corpo(palavra) do cineasta. Em Vinte Navios, Guerra se diz "um eterno estrangeiro dentro de si mesmo". Ziza Dourado explica também como o aspecto visceral do sujeito é explorado em seus filmes, repletos de corpos que reagem pela carne à lógica opressora do poder (caso, por exemplo, de A Queda). Os corpos, e as imagens dos corpos, no entanto, também resistem.

A relação entre o corpo - o corpo individual e o corpo coletivo do povo - e a terra é explorada por Vitor Zan (Universidade Sorbonne Nouvelle - Paris 3) a partir de Os Fuzis (1963), Os Deuses e os Mortos (1970) e A Queda (1977), que compõem, a exemplo de Glauber Rocha, a "trilogia da terra" de Guerra. Os corpos dos personagens - corpos oprimidos, corpos migrantes, corpos ensanguentados, corpos resistentes - transformam-se em território. Zan mostra como "as relações interterritoriais se estabelecem, nesses três filmes de Ruy Guerra, tanto intradiegeticamente, por exemplo pela chegada de soldados em Milagres (n'Os Fuzis) ou pelo tema da migração (em Os Deuses e os Mortos), quanto entre os filmes, na trajetória que se traça entre um e outro, ou ainda na migração interfílmica de imagens, empregada sobretudo em A Queda."

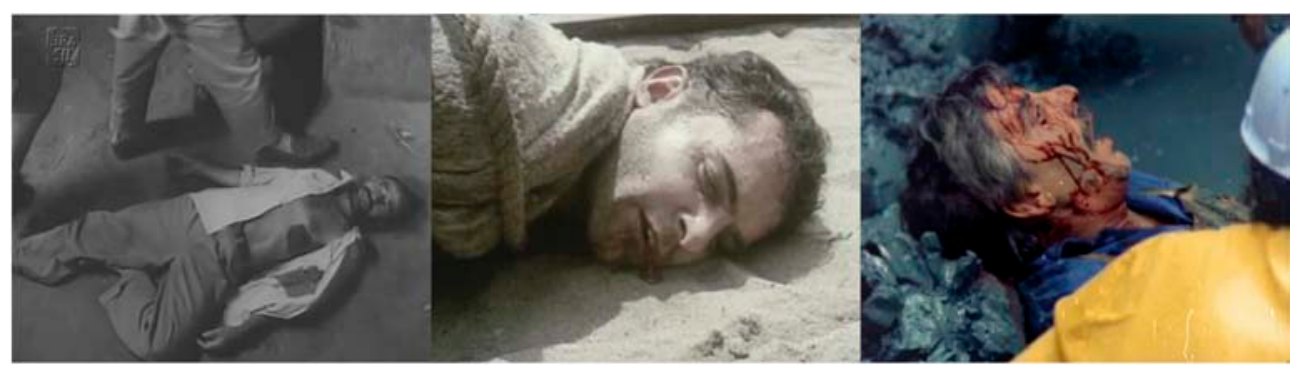

Imagem 2: Corpos caídos: Os Fuzis, Os Deuses e os Mortos e A Queda | (C) Ruy Guerra 
O corpo que cai de A Queda, para Reinaldo Cardenuto (Fundação Armando Álvares Penteado, São Paulo), representa o despencar de um povo e de um projeto de povo; o colapso de um projeto revolucionário sugerido em Os Fuzis antes do golpe militar no Brasil $^{12}$. O corpo político do povo ganha a "figura totêmica" que abre o filme: o boi no matadouro. O cinema político, por sua vez, ao invés de "projetar futuros" possíveis, revela a crise que se instala no presente.

\section{Moçambique, meu amor}

Após A Queda, Guerra dirige-se a Moçambique, passando por Portugal. Inês Cordeiro da Silva (UCLA) contextualiza o cinema de Guerra nesse movimento tricontinental entre o Cinema Novo brasileiro e o cinema nascente moçambicano. Como escrevem os organizadores, entre 1977 e 1986, "de regresso ao seu país natal, onde vivera até aos vinte anos, Guerra é o principal artesão da fundação do cinema nacional moçambicano". A investigadora descreve sobretudo as relações estéticas e políticas de um caminho que vai de Os Fuzis a Mueda, Memória e Massacre. Segundo ela, Guerra complexifica, por exemplo, a fusão entre o documentário e a ficção, e desenvolve as formas da "estetika da fome" anunciada em Os Fuzis.

Maria do Carmo Piçarra (Universidade do Minho, Universidade de Lisboa, Universidade de Reading) parte dessa problemática para discutir "a genealogia da emergência dos cinemas novos mas também sobre o ideal que toma o filme como arma para mudar a sociedade e, no caso das ex-colónias portuguesas, fixar o nascimento das novas nações”. Primeiro, ela interroga a relação entre Ruy Guerra e os cineastas da Rive Gauche, sobretudo Jean-Luc Godard, que passou por Moçambique. A autora afirma que "se a Nouvelle Vague mudou a perspectiva sobre o cinema questionando a sua concepção de uma indústria do espetáculo, o Terceiro Cinema (e o Cinema Novo) contribuíram para mudar o modo de fazer cinema dos autores da Rive Gauche”, invertendo a lógica de pensar as influências e os ecos temáticos e estéticos entre o cinema europeu e os "outros" cinemas. Para Mateus Araújo, ainda, talvez seja a convivência com Guerra o elo que falta para compreender o "diálogo truncado" e as trocas cinematográficas entre Godard e Glauber Rocha (ele cita, por exemplo, O Vento do Leste, de Godard, 1970, e O Leão de Sete Cabeças, de Rocha, 1970). Qual é o caminho do cinema político? Na Europa e na América Latina, eles não podem ser os mesmos. No subdesenvolvimento, escolhe-se outra "margem". Como mostra Piçarra, no entanto, a de Guerra, em qualquer parte, nos termos de Gilles Deleuze e Félix Guattari, é a de um cinema "menor".

\footnotetext{
${ }^{12}$ Ver Reinaldo Cardenuto. 2014. O Cinema Político de Leon Hirszman (19761981): Engajamento e Resistência durante o Regime Militar Brasileiro. Tese de doutoramento. ECA-USP. p. 337.
} 
Essa passagem de Guerra por Moçambique é melhor contextualizada no interior do cinema revolucionário por Ros Gray (Goldsmiths College) e Robert Stock (Universität Konstanz). Gray realiza uma arqueologia da busca moçambicana pelo nascimento de um cinema para o nascimento de uma nação. Ela identifica, por exemplo, os processos históricos do cinema cubano e do cinema argelino como bases para o moçambicano, e situa o nascente cinema do país no interior dos movimentos anticolonialistas. Contudo, para essa arqueologia, Gray reclama a importância da análise da singularidade de cada revolução, olhando principalmente através do que a desmantela e interrompe. Como, nesse movimento, as imagens intermedeiam relações de poder? Stock, por sua vez, aproxima-se do contexto de libertação moçambicana a partir dos testemunhos filmados por Guerra durante o julgamento dos antigos colaboradores e oficiais do colonialismo. As imagens são a matéria da série $O s$ Comprometidos. Pertencentes ao INC, foram compiladas em Treatment for Traitors (Ike Bertels, 1982). Stock relaciona o dispositivo do testemunho a Mueda, Memória e Massacre, mas também a Os Comprometidos. Tal "acumulação de material de memória" oral realizado por Guerra enfatiza as experiências subjetivas, mas, confrontada aos limites do presente e a seu tornar-se passado, "a promessa do testemunho é ambivalente”.

A história do cinema moçambicano, que se confunde com as atividades de Guerra nesse período, é, porém, narrada por José Luiz Cabaço. Cabaço oferece um verdadeiro testemunho (aqui realizado com um certo distanciamento crítico) para a historiografia do cinema de Moçambique. Retraçando cronologicamente o nascimento do cinema nacional, Cabaço reflete, de um lado, sobre o projeto revolucionário e, de outro, sobre sua realização pelo INC. Segundo ele, as preocupações urgentes giravam em torno da criação de um registo visual, da construção de uma unidade nacional por meio da circulação de imagens através do território moçambicano, e da formação técnica e estética de jovens. O INC tinha como lema produzir a imagem do povo para restituir a imagem ao povo. Cabaço discute então a grande importância da produção do jornal cinematográfico Kuxa Kanema (o "nascimento do cinema”, criado em 1976). Nos anos 1980, tem-se uma nova experiência do cinema moçambicano, que passa a circular pelo continente africano. Segundo ele, a procura por uma linguagem audiovisual também deu origem a outras iniciativas além do cinema.

Do trabalho de Guerra, Cabaço destaca o programa independente "Cinema nas Aldeias", relacionado ao projeto de cinema móvel do $\mathrm{INC}^{13}$. Ainda sobre a experiência de Mueda, ele conta: "Ruy ficou fascinado com essa evocação festiva de uma tragédia”. Em África, o

\footnotetext{
${ }^{13}$ Raquel Schefer escreve: "Procurava-se criar estruturas de exibição fixas nas aldeias precisamente para que o programa do cinema móvel deixasse de ser apenas móvel."
} 
limite entre o riso e o choro é muito tênue, o ritual fúnebre é seguido de festejo. A morte é passagem, e os espíritos são interlocutores do quotidiano. Com Mueda, Guerra também se afasta da FRELIMO. Acerca da história conturbada do filme, Cabaço confessa que "Ruy mexeu num ninho de abelhas".

Ademais, face a um cinema da precariedade, Cabaço se preocupa com a sobrevivência e a preservação das imagens realizadas nos anos 1970 e 1980 no Arquivo Nacional Moçambicano. As mais de 40 horas do julgamento de Os Comprometidos, por exemplo, "devem estar numa cave...”. Qual será o destino do cinema da libertação?

\section{A construção do olhar}

Ismail Xavier ${ }^{14}$ realiza uma análise aprofundada de Estorvo (2000), filme que diverge dos códigos do cinema dominante adotados pelo cinema da Retomada no Brasil. Num "território de violência e anomia social", Guerra explora a subjetividade do protagonista em crise. Xavier demonstra como o cineasta constrói formalmente "o estranhamento do mundo e a solidão" desse "moço de família que se movimenta pelo espaço urbano como que perseguido por um olhar imaginário e por ameaças que mal compreende". Para Xavier, "o estatuto da voz narrativa" em primeira pessoa "se altera, pois há um contexto imagético e sonoro que ultrapassa a enunciação vocal". Guerra fabrica visualmente um universo urbano sombrio, grotesco, instável. Filmado em Havana, Lisboa e Rio de Janeiro, o território imaginário é transnacional e fragmentado. Tem-se um personagem em trânsito, um "autoexilado", que confronta as normas e as estruturas fixas da sociedade. Nessa narrativa feita de circularidades, não parece haver saída. Personagem e espectador terminam míopes, incapazes de realizar a fuga desejada. Aqui, não se trata de uma queda, mas de uma imobilidade diante do real, de uma possibilidade postiça de redenção.

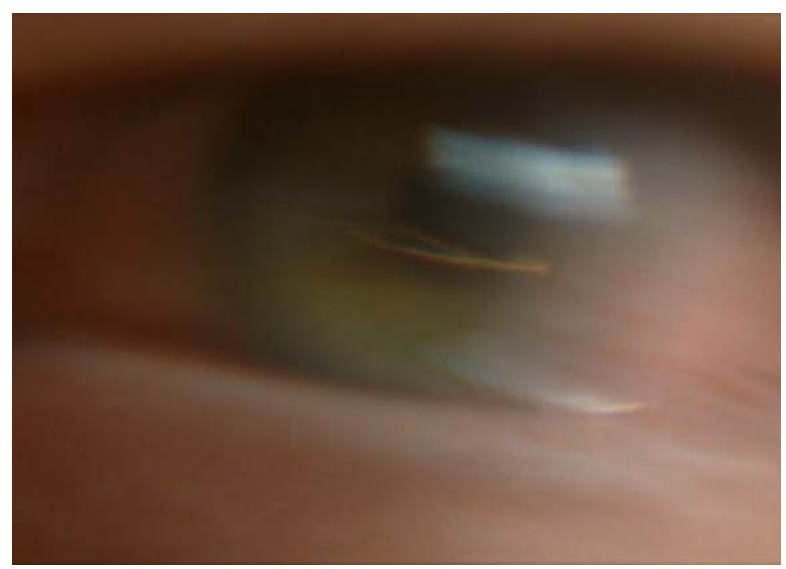

Imagem 3: Estorvo: poder ver | (C) Ruy Guerra, Riofilme

\footnotetext{
${ }^{14}$ Comunicação lida por Mateus Araújo.
} 
Jorge la Ferla, finalmente, descreve o projeto pedagógico de Guerra. Ele realiza uma reflexão e uma breve historiografia do ensino do cinema no Brasil e na América Latina, destacando o papel do cineasta. Sempre à margem, Guerra pratica seu próprio método didático, a partir do qual pode-se estabelecer um "pensamento crítico dos estudos cinematográficos".

\section{Em direção a um pensamento crítico das imagens}

Como escreve Maria do Carmo Piçarra, "Guerra não carrega em si, como propõem Deleuze e Guattari, um 'povo por vir'. Não o faz porque a sua atitude não radica na racionalidade. Parte, sim, do que chama 'um acto de sobrevivência' ou de fé no sentido de uma convicção profunda que é a de acreditar na vida". Em "Um Poema Antilírico", lido por Rita Chaves, ele escreve, "hoje não há mais poesia, mas essa certeza de lutar junto aos que lutam”.

Assim, debruçar-se sobre o pensamento crítico das imagens a partir da obra de Ruy Guerra consiste certamente em colocar-se diante de um chamado - um chamado à arte e à luta: "guerra é guerra" 15 .

\section{Post Scriptum}

Em uma das semanas de maio de 2016 que antecedem a publicação desta recensão, algumas imagens circularam pela imprensa e pelas redes sociais da "gente de cinema" do Brasil. Era Ruy Guerra, em seus 84 anos, de pé, óculos escuros, punho cerrado levantado, megafone na mão, em meio à ocupação do prédio da Funarte no Rio de Janeiro. Guerra juntou-se aos artistas que protestavam contra o governo interino (ilegítimo, golpista) de Michel Temer, cujo primeiro ato foi a extinção do Ministério da Cultura brasileiro. Em entrevista à organização do movimento, Guerra declarou: "Um povo sem cultura é um povo vencido". É preciso levar os instrumentos da cultura a todos os cantos do país, para que o povo possa pensar o que é, e o que quer ser - disse ele. É preciso lutar contra o sufocamento das vozes populares.

\footnotetext{
${ }^{15}$ Frase dos diálogos de Os Fuzis e A Queda, retomada no colóquio por Ziza Dourado.
} 